\title{
Nevirapine use to reduce mother-to-child transmission of HIV in Canada
}

\author{
Committee for Canadian Paediatric AIDS Research Group*
}

$\mathrm{N}_{\mathrm{i}}^{\mathrm{e}}$ evirapine (NVP) is a non-nucleoside reverse transcriptase inhibitor (NNRTI) that is used to treat adults and children with human immunodeficiency virus (HIV) infection. The drug was licensed in Canada in September 1998 and has been widely used in combination antiretroviral therapy regimens, usually along with two nucleoside reverse transcriptase inhibitors. NVP is, generally, well tolerated; however, up to $20 \%$ of patients may develop rash, with a severe rash occurring in $6 \%$ of patients and Stevens-Johnson syndrome reported in $0.5 \%$ of patients. A large number of NNRTI mutations have been documented, and a single mutation, K103N, confers a degree of broad NNRTI resistance. Distinctions occur in resistance patterns to different NNRTIs (1).

More recently, NVP has been used during pregnancy, both as a part of combination regimens to treat maternal HIV infection and for perinatal chemoprophylaxis to reduce mother-tochild transmission. The drug has several characteristics that make it attractive for use in perinatal HIV chemoprophylaxis. These characteristics include potent, rapid antiviral activity; rapid absorption across the gastrointestinal tract, placenta and blood brain barrier; a long half-life after a single dose (median 61 to $66 \mathrm{~h}$ in pregnant women and 45 to $64 \mathrm{~h}$ in infants); availability in both tablet and suspension formulations; and a relatively inexpensive cost.

There have been recent reports of serious adverse events attributed to NVP-containing regimens for postexposure pro- phylaxis, including hepatotoxicity and skin reactions (2). No serious toxicity has been reported among mother-infant pairs using this regimen for the prevention of perinatal transmission. Combination antiretroviral regimens containing NVP may be used in HIV-infected persons after considering the risks and benefits, and monitoring adverse reactions (2).

A number of studies, designed to assess the potential efficacy of shorter and less expensive perinatal prophylactic regimens, have been conducted in developing countries (3). A recent study in Uganda (HIVNET 012) involving breastfeeding, HIV-infected women, showed that a single $200 \mathrm{mg}$ dose of NVP given to a mother at the onset of labour, combined with a single $2 \mathrm{mg} / \mathrm{kg}$ oral dose of NVP given to her infant at 48 to $72 \mathrm{~h}$ of age, reduced transmission by nearly $50 \%$ at six to eight weeks after birth compared with a very short regimen of zidovudine (ZDV) given orally during labour and to the infant for one week after birth (4). Transmission at age 12 months was $15.7 \%$ in the NVP group compared with $24.1 \%$ in the ZDV group, with relative risk reduction of $39 \%$ (5). Resistance to NVP was detected six weeks after birth in seven of $30(23 \%)$ women and seven of 16 (44\%) HIV-infected infants. Resistance patterns in mothers did not always match the patterns in their infants (6).

As a result of the studies on shorter and less expensive chemoprophylaxis regimens mentioned above, there have been recent changes in therapeutic guidelines in the United

*Drs Jack Forbes, University of British Columbia, Vancouver, British Columbia (principal author); Upton Allen, University of Toronto, Toronto, Ontario; Brian Conway, University of British Columbia, Vancouver, British Columbia; Joanne Embree, University of Manitoba, Winnipeg, Manitoba; Susan King, University of Toronto, Toronto, Ontario; Normand Lapointe, University of Montreal, Montreal, Quebec; Stanley Reid, University of Toronto, Toronto, Ontario; Lindy Samson, University of Ottawa, Ottawa, Ontario

Correspondence: Infectious Diseases and Immunization Committee, Canadian Paediatric Society, 2204 Walkley Road, Suite 100, Ottawa, Ontario K1G 4G8. Telephone 613-526-9397, fax 613-526-3332, Web site http://www.cps.ca 
States for HIV-infected women in labour who received no previous therapy (7) and in British Columbia for women who have a detectable viral load at delivery (8). In these situations, a number of options for antiretroviral therapy during labour are available, as follows:

A. A single dose of NVP (200 mg) is given orally at the onset of labour, followed by a single dose of NVP $(2 \mathrm{mg} / \mathrm{kg}$ ) given to the newborn at age $48 \mathrm{~h}$. This regimen is based on the HIVNET 012 study. The efficacy of NVP is unknown if the mother has a NVP-resistant virus.

B. Oral ZDV and 3TC are administered during labour, followed by one week of oral ZDV and 3TC given to the newborn. This regimen is based on the PETRA study (9); it has the potential toxicity that is associated with multiple drug exposure.

C. Intrapartum intravenous ZDV is given during labour based on the AIDS Clinical Trials Group 076 protocol (10), followed by six weeks of ZDV for the newborn. This regimen is based on epidemiological data compared with no ZDV treatment; due to the intravenous therapy component, there are administration and adherence issues.

D. A two-dose NVP regimen is combined with intrapartum intravenous ZDV and six weeks of ZDV for the newborn. This regimen is a theoretical consideration that combines regimens $\mathrm{A}$ and $\mathrm{C}$; it has unknown efficacy and limited toxicity data.

NVP may be considered in perinatal chemoprophylaxis in the following circumstances:

- as a component of combination antiretroviral therapy given during pregnancy;

- $\quad$ as a single dose given during labour to women who had no previous therapy or who have a detectable viral load at delivery; and
- $\quad$ as a single postpartum dose administered to infants born to mothers who received no therapy or who received chemoprophylaxis at delivery only. Combined therapy using ZDV and NVP may be beneficial in this circumstance.

\section{REFERENCES}

1. Larder B. New insights into genetic mechanism of HIV drug resistance. Sixth Conference on Retroviruses and Opportunistic Infections. Chicago, January 31 to February 4, 1999.

2. Serious adverse events contributed to nevirapine regimes for post-exposure prophylaxis after HIV exposures - worldwide, 1997 to 2000. MMWR Morb Mortal Wkly Rep 2001;49:1153-63.

3. Periperl L. Antiretroviral teatments to reduce mother-to-child transmission of HIV. < hivinsite.ucsf.edu/topics/ pregnancy and childbirth/perinatal transmission/ 3098.0098. $\mathrm{htm} \overline{\mathrm{l}}>$ (Version current $\overline{\text { at }}$ August 25, 2000)

4. Guay L, Musoke P, Fleming T, et al. Intrapartum and neonatal single-dose nevirapine compared with zidovudine for prevention of mother-to-child transmission of HIV-1 in Kampala, Uganda: HIVNET 012 randomised trial. Lancet 1999;354:795-802.

5. Owor M, Deseyve M, Fleming T, et al. The one year safety and efficacy data of the HIVNET 012 trial. XIII International AIDS Conference. Durban, South Africa. July 10 to 14, 2000. (Abst)

6. Jackson J, Mracna M, Guay L, et al. Selection of nevirapine resistance mutations in Uganda women and infants receiving MVP prophylaxis to prevent HIV-1 vertical transmission (HIV NET 012). XIII International AIDS Conference. Durban, South Africa. July 10 to 14, 2000.

7. United States Public Health Service Task Force Recommendations for the Use of Antiretroviral Drugs in Pregnant Women Infected with HIV-1 for Maternal Health and for Reducing Perinatal HIV-1 Transmission in the United States. (Revised February 25, 2000) <www.hivatis.org> (Version current at November 3, 2000)

8. Money D, Forbes J, Meneilly G, Burdge D. Guidelines for Antiretroviral Use in Pregnancy. British Columbia Centre for Excellence in HIV/AIDS. Therapeutic Guidelines (Revised April 2000) <www.cfeweb.hivnet.ubc.ca>

9. Saba J. The results of the PETRA intervention trial to prevent perinatal transmission in Sub-Saharan Africa. Sixth Conference on Retroviruses and Opportunistic Infections. Chicago, January 31 to February 4, 1999.

10. Connor E, Sperling R, Gelber R, et al. Reduction of maternalinfant transmission of human immunodeficiency virus type 1 with zidovudine treatment. Pediatric AIDS Clinical Trials Group Protocol 076 Study Group. N Engl J Med 1994;331:1173-80. 


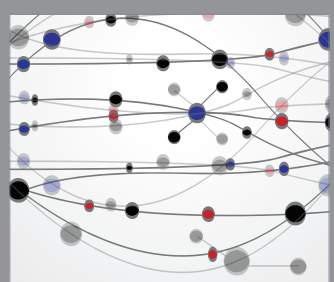

The Scientific World Journal
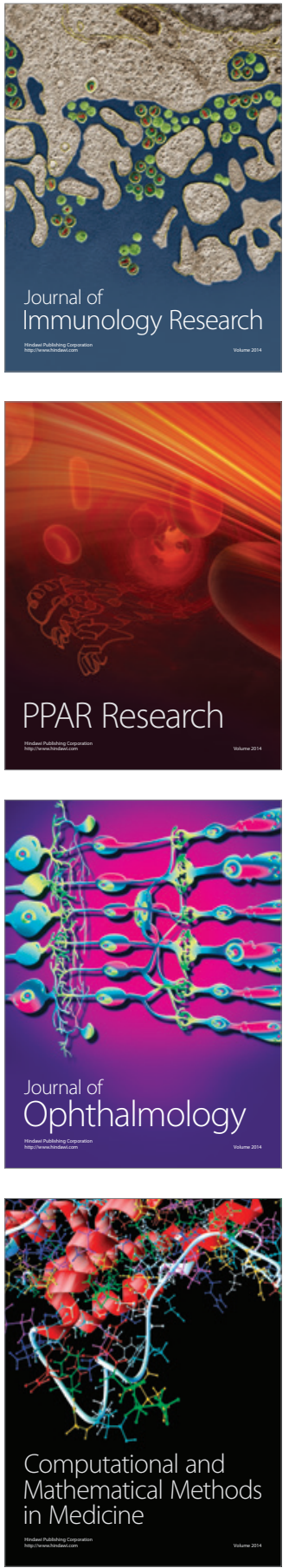

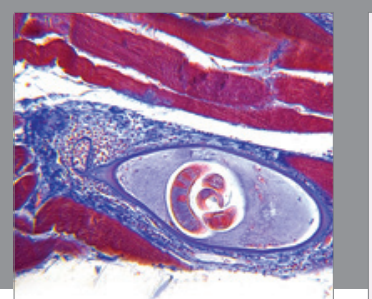

Gastroenterology Research and Practice

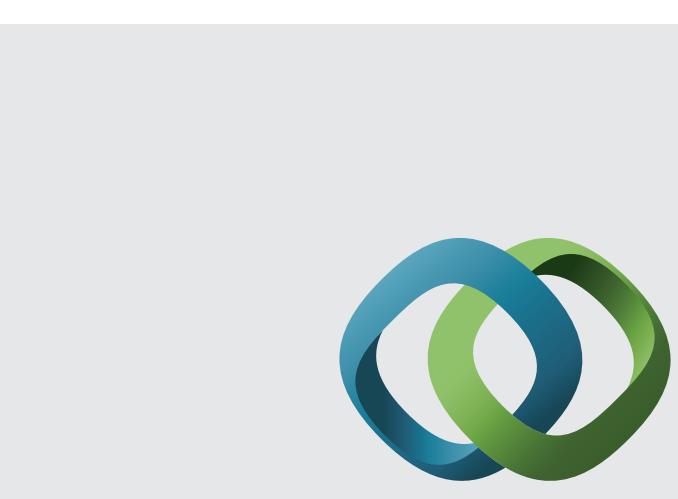

\section{Hindawi}

Submit your manuscripts at

http://www.hindawi.com
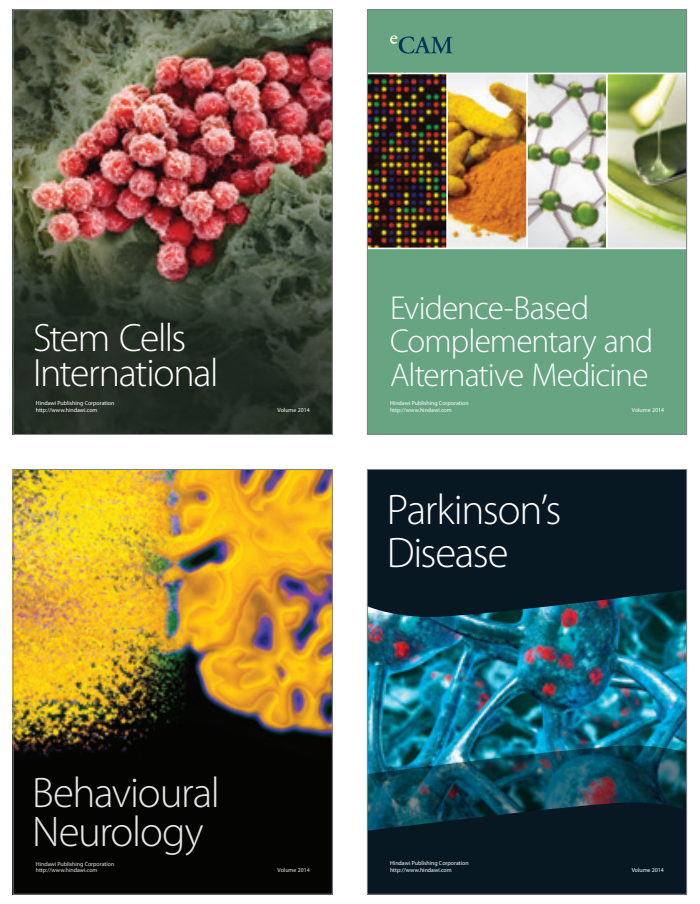
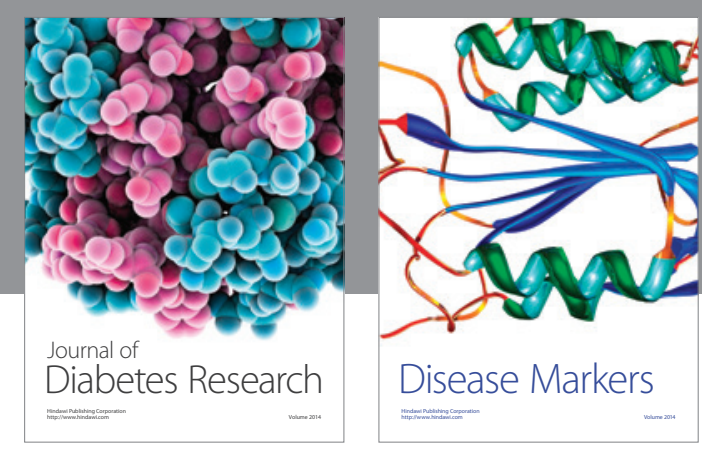

Disease Markers
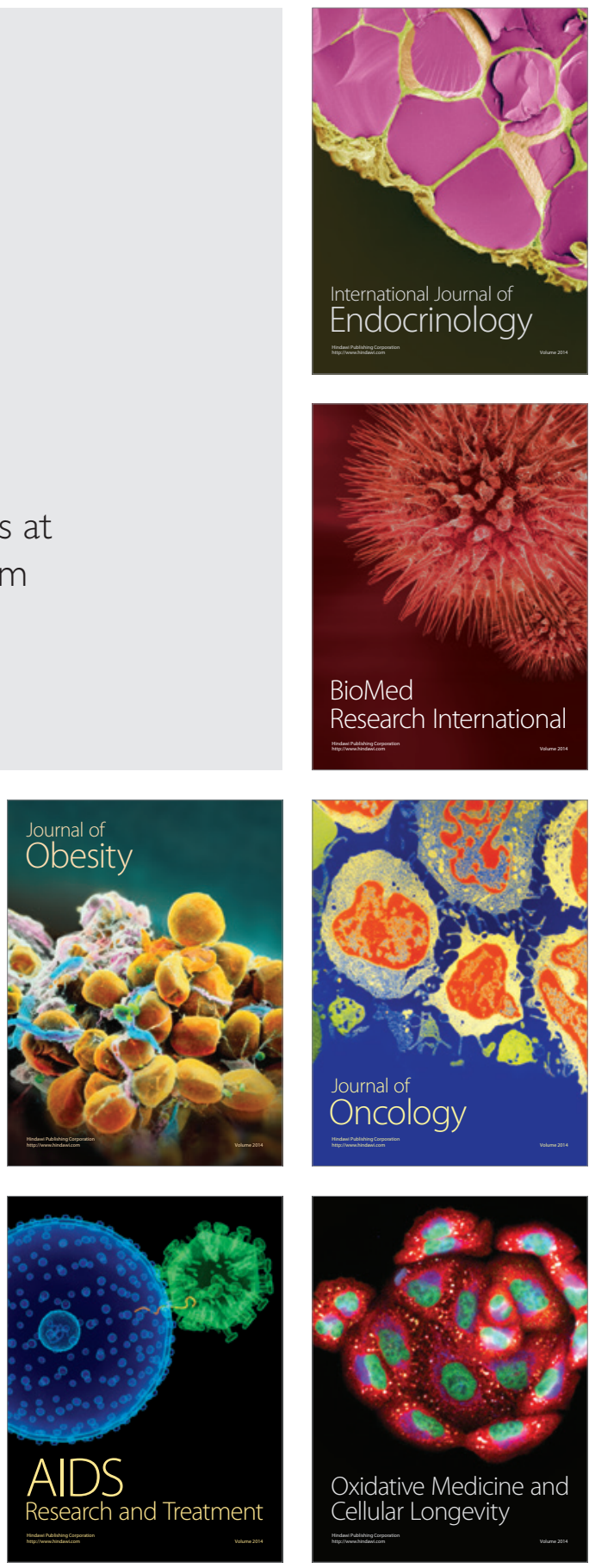